\title{
Occurrence of synthetic phenolic antioxidants and transformation products in urban and rural indoor dust ${ }^{\text {is }}$
}

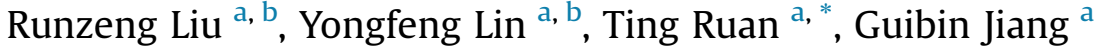 \\ a State Key Laboratory of Environmental Chemistry and Ecotoxicology, Research Center for Eco-Environmental Sciences, Chinese Academy of Sciences, \\ Beijing 100085, China \\ ${ }^{\mathrm{b}}$ University of Chinese Academy of Sciences, Beijing 100049, China
}

\section{A R T I C L E I N F O}

\section{Article history:}

Received 27 October 2016

Received in revised form

22 November 2016

Accepted 25 November 2016

\section{Keywords:}

Synthetic phenolic antioxidants

BHT

Transformation products

Indoor dust

Estimated daily intake

\begin{abstract}
A B S T R A C T
In this study, seven synthetic phenolic antioxidant (SPA) analogues were positively found in urban and rural indoor dust samples collected from Shandong province in China, among which the novel 2,4,6-tritert-butylphenol (AO 246), 2,6-di-tert-butyl-4-sec-butylphenol (DTBSBP), 2,4-di-tert-butylphenol (DBP) and 4,4'-butylidenebis (2-(1,1-dimethylethyl)-5- methyl-phenol) (AO 44B25) analogues accounted for $29 \%$ of total SPA concentrations ( $\sum$ SPAs). Urban dust showed significantly higher $\sum$ SPA levels (range: $1.56 \mathrm{e} 3-2.03 \mathrm{e} 4 \mathrm{ng} / \mathrm{g}$ ) compared with those in rural indoor dust (668-4.39e3 ng/g, $\mathrm{p}<0.05)$. 2,6-Di-tertbutyl-4-methylphenol (BHT) was the dominate analogue in the urban indoor dust, which constituted of $74 \%$ in $\Sigma$ SPAs. While, varied composition profiles of SPAs were noticed in rural indoor dust, for instance, AO 246 (46\%) and BHT (43\%) had similar contributions to $\sum$ SPAs. Three BHT transformation products (TPs) were also detected in most of the urban and rural dust samples ( $>97 \%$ ), with individual residue level in the same order: 2,6-di-tert-butyl-1,4-benzoquinone (BHT-Q) > 2,6-di-tert-butyl-4-hydroxy- 4methyl-2,5-cyclo-hexadienone (BHT-quinol) > 3,5-di-tert-butyl-4-hydroxybenzal-dehyde (BHT-CHO). Geometric mean values of total TP concentrations were $555 \mathrm{ng} / \mathrm{g}$ and $131 \mathrm{ng} / \mathrm{g}$ for urban and rural indoor dust samples, respectively. A preliminary estimated daily intake calculation at dust ingestion scenario suggested additional concerns might be paid to simultaneous exposure of several SPA analogues and TPs besides current focus on BHT exposure risks.
\end{abstract}

(C) 2016 Elsevier Ltd. All rights reserved.

\section{Introduction}

The environmental occurrence and human exposure of new anthropogenic chemicals have received increasing public scrutiny in recent years, especially for the high production volume (HPV) chemicals with wide commercial applications (Howard and Muir, 2010; Muir and Howard, 2006). Among the various HPV chemicals, an increasing awareness has been raised to the synthetic phenolic antioxidants (SPAs), which are largely used in rubber, plastic, cosmetic formulations, and pharmaceuticals to retard the oxidation process (Demertzis and Franz, 1998; Rodil et al., 2010). SPAs generally present a basic common structure that the phenolic ring is substituted with hindered alkyl groups in ortho-positions of the aromatic ring (Brocca et al., 2002). Addition of SPAs is the most

\footnotetext{
* This paper has been recommended for acceptance by Dr. Chen Da.

* Corresponding author.

E-mail address: tingruan@rcees.ac.cn (T. Ruan).
}

commonly used method to retard the oxidation reactions that undergo in all polymeric materials (Rodil et al., 2010).

As additives in polymer matrices, SPAs are likely to leach out by abrasion and volatilization to contaminate the surrounding environment in a manner similar to other additives such as organic phosphate flame retardants and photoinitiators (Liu et al., 2016; Wei et al., 2015). Migrations of certain SPA analogues, i.e. 2,6-ditert-butyl-4-methylphenol (BHT) and 3-tert-butyl-4hydroxyanisole (BHA), from packing materials to the contacting water and food simulants (3\% actetic acid, $10 \%$ ethanol and oil) have been proved in previous studies (Brocca et al., 2002; Gao et al., 2011). BHT was the primary targeted SPA pollutant of concern, which was frequently found in environmental matrixes such as river water, sewage influent and effluent with concentrations varying from part-per-trillion (ppt) to part-per-million (ppm) (Fries and Puttmann, 2004; Liu et al., 2015a; Rodil et al., 2010). A study on the measurement of organic pollutants in indoor environment in Sweden showed that BHT was among contaminates of the highest residue levels in indoor dust, with a mean concentration of $70 \mu \mathrm{g} / \mathrm{g}$ 
(Nilsson et al., 2005). Meanwhile, other SPA analogues, such as 4,4'butylidenebis (2-(1,1-dimethylethyl)-5-methyl-phenol) (AO 44B25), 1,3,5-trimethyl-2,4,6-tris(3,5-di-tert-butyl-4hydroxybenzyl)benzene (AO 330) and 2,2'-methylenebis (4methyl-6-tert-butylphenol) (AO 2246), were recently identified in sludge sewage as emerging pollutants (Liu et al., 2015b).

Usage of SPA compounds triggered concerns on the toxic potentials. Long-term exposure of 2,4,6-tri-tert-butylphenol (AO 246) was demonstrated to cause liver injury in rats (Matsumoto et al., 1991). Prenatal exposure to AO 44B25 in rats was reported to affect the central nervous system of rat offspring (Takahashi and Oishi, 2006). BHA can modulate and disrupt the endocrine system, and sufficient evidence was found for its carcinogenicity in experimental animals (Grice, 1988; Whysner and Williams, 1996). The effects of BHT consumption on human health are controversial, since some studies indicated a potential link between BHT and cancer, while other studies did not find the relationship (Botterweck et al., 2000; Witschi, 1986).

The quality of indoor environment is crucial to human health as people spend approximately $90 \%$ of time indoors (Klepeis et al., 2001). Although mounting evidence showed the importance of indoor dust ingestion as a pathway of human exposure to organic pollutants (Meng et al., 2016; Qi et al., 2014; Wei et al., 2015), there is hitherto little data on indoor concentration levels of SPAs, especially for the analogues with high hydrophobicity and low volatility, which might be easy to absorb on indoor dust and accumulate in human body through dust ingestion. Therefore, the aims of the current study are (a) to report residue levels and composition profiles of novel SPAs and relevant transformation products (TPs) in urban and rural indoor dust; (b) to assess potential risk of human exposure to SPAs via ingestion of indoor dust.

\section{Materials and methods}

\subsection{Materials}

Analyte name, structure, abbreviation and other relevant information of the target SPA analytes are shown in the Supporting Information (Table S1). AO 22E46 was supplied by AccuStandard (New Haven, CT). BHT-quinol was purchased from Frontier Scientific Inc. (Logan, UT). Standards of the other analytes were purchased from TCI (Tokyo, Japan). Isotope-labeled standards of 2,6-di(tert-butyl-d9)-4-methyl (phenol-3,5,O-d3) (BHT-d21) and ${ }^{13} \mathrm{C}$ tetrabromobisphenol A $\left({ }^{13} \mathrm{C}_{12}\right.$-TBBPA) were bought from Cambridge Isotope Laboratories (Andover, MA). The purities for all the target analytes were $95 \%$ or higher. Silica gel (100-200 mesh size) supplied by Merck (Darmstadt, Germany) was activated at $550{ }^{\circ} \mathrm{C}$ for $12 \mathrm{~h}$, and $5 \%$ water-deactivated prior to use. Anhydrous sodium sulfate $\left(\mathrm{Na}_{2} \mathrm{SO}_{4}\right)$ bought from Sinopharm (Shanghai, China) was baked at $600{ }^{\circ} \mathrm{C}$ for $6 \mathrm{~h}$ and stored in a sealed desiccator. HPLCgrade hexane (Hex), dichloromethane (DCM) and methanol (MeOH) were obtained from J.T. Baker (Phillipsburg, NJ). Ultrapure water $\left(\mathrm{H}_{2} \mathrm{O}, 18.3 \mathrm{M} \Omega \times \mathrm{cm}\right)$ was generated from Milli-Q purification system (Billerica, MA).

\subsection{Sample collection}

Individual dust sample was obtained from each of the 75 resident houses in Jinan city ( $\mathrm{n}=55$, the capital of Shandong province, China) and the surrounding rural area $(n=20)$ in May 2014. According to statistical data from the local government, the per-capita income of urban residents was 2.6 folds higher than rural residents (Statistical bulletin, 2014). The urban houses were equipped with more furniture and electronics than rural houses. Each dust was a mixed sample collected from surfaces in the living room, with an average temperature of $24{ }^{\circ} \mathrm{C}$. Approximately a $0.5 \mathrm{~g}$ indoor dust was easily obtained from surfaces of upholstery, furniture, stand fans, and windowsills in each house using wool paint brushes, which covered an area of several square meters. All samples were swept onto aluminum foil, sealed in polyethylene zip bags, and transported back to our lab immediately. Hair in the dust was removed using clean tweezers. Large debris was removed by stainless steel testing sieves to collect dust particles $<150 \mu \mathrm{m}$ in size. To prevent cross-contamination, the wool paint brushes, sieves and tweezers were washed pre- and between sampling intervals by $\mathrm{MeOH}$ and ultrapure water, and then air-dried. The dust samples were stored at $-20^{\circ} \mathrm{C}$ until pretreatment and instrumental analysis.

\subsection{Sample preparation and quantitative analysis}

The dust samples were extracted by accelerated solvent extraction (ASE), and the dust extracts were cleaned by silica gel packed columns as mentioned elsewhere (Liu et al., 2015a). Briefly, $0.5 \mathrm{~g}$ of sample (spiked with $200 \mathrm{ng}$ BHT-d21 and $10 \mathrm{ng}{ }^{13} \mathrm{C}-\mathrm{TBBPA}$ ) was mixed with $15 \mathrm{~g}$ of $\mathrm{Na}_{2} \mathrm{SO}_{4}$ and extracted by DCM/Hex $(3: 1, \mathrm{v} / \mathrm{v})$ using an accelerated solvent extractor (ASE 350, Dionex Inc., Sunnyvale, CA). The extraction was conducted at $90^{\circ} \mathrm{C}$ and 1500 psi and repeated in three cycles. The dust extracts were concentrated by rotary evaporation to $\sim 2 \mathrm{~mL}$ and fractioned on glass columns packed with $8 \mathrm{~g}$ of silica gel. Before dust extract loading, the silica gel packed columns were preconditioned by $30 \mathrm{~mL}$ of Hex. Then the concentrated extracts were loaded and eluted by $120 \mathrm{~mL}$ of DCM/ Hex mixture $(1: 1, v / v)$. The $120 \mathrm{~mL}$ eluates were then concentrated and solvent exchanged into $5 \mathrm{~mL}$ of $\mathrm{MeOH}$. Finally, $20 \mu \mathrm{L}$ of the sample was injected into the instrument for quantification analysis.

The 2695 high performance liquid chromatography coupled with a Quattro Premier XE triple-quadrupole mass spectrometer (HPLC-MS/MS, Waters, Milford, MA) was used for quantification of the target analytes. The mass spectrometer was operated in negative electrospray ionization (ESI) mode. Source and desolvation temperatures were kept at $120{ }^{\circ} \mathrm{C}$ and $450{ }^{\circ} \mathrm{C}$, respectively. Desolvation gas flow was $800 \mathrm{~L} / \mathrm{hr}$, and cone gas flow was $50 \mathrm{~L} / \mathrm{hr}$. The argon pressure in the collision cell was set at $3.8 \times 10^{-3}$ mbar for MS/MS measurement. Detailed information on the monitored ion transitions and optimized parameters for each analyte is shown in the Supporting Information (Table S2). A SymmetryShield ${ }^{\mathrm{TM}} 5 \mu \mathrm{m}$ C18 analytical column $(150 \times 2.1 \mathrm{~mm}$, Waters, Milford, CT $)$ was selected for the chromatographic separation, with $\mathrm{MeOH}$ and $\mathrm{H}_{2} \mathrm{O}$ chosen as mobile phases. The column temperature was set at $40^{\circ} \mathrm{C}$, and flow rate for the separation procedure was $0.3 \mathrm{~mL} / \mathrm{min}$. The gradient was started at a composition of 25:75 $\left(\mathrm{MeOH} / \mathrm{H}_{2} \mathrm{O}, \mathrm{v} / \mathrm{v}\right)$. It was first held for $5 \mathrm{~min}$, after which the $\mathrm{MeOH}$ was linearly increased to $100 \%$ in $10 \mathrm{~min}$ and then held for another $10 \mathrm{~min}$. After returning to the initial composition, the column was allowed to reequilibrate for $3 \mathrm{~min}$.

\subsection{Quality assurance/quality control}

In order to evaluate the extraction efficiency, 10 dust samples were randomly selected for a fourth extraction. No quantifiable amounts of the target SPAs and TPs were found in the fourth extraction, indicating maximum recoveries of target analytes in the three extraction cycles. Quantification of the analytes was based on external calibration curves, and potential losses during the sample preparation were corrected by the isotopic-labelled standards. As shown in Table S3, concentrations of the single phenolic ring analytes were corrected by BHT-d21, and those of the other SPAs were corrected by ${ }^{13} \mathrm{C}_{12}$-TBBPA. Recoveries of the target analytes in matrix-spiked dust samples at $200 \mathrm{ng} / \mathrm{g}$ varied from 65\% (AO 4426) 
to $103 \%$ (4-tOP), with an average value of $89 \%$. The relative standard deviations (RSDs, $\mathrm{n}=5$ ) were all less than $15 \%$. One procedural blank ( $15 \mathrm{~g} \mathrm{Na}_{2} \mathrm{SO}_{4}$ ) was included in every batch of eight samples to check for the potential target contamination in the sample preparation. Results showed that all target analytes in the blanks were below method quantification limits (MQLs), which were calculated as a signal-to-noise ratio of 10 and ranged from $0.1 \mathrm{ng} / \mathrm{g}$ (AO 425) to $10 \mathrm{ng} / \mathrm{g}$ (BHT). Instrumental calibration was carried out by injection of seven calibration levels (varying from $20 \mathrm{ng} / \mathrm{g}$ to $2000 \mathrm{ng} / \mathrm{mL}$ for BHT, and $0.5 \mathrm{ng} / \mathrm{g}$ to $100 \mathrm{ng} / \mathrm{mL}$ for others), and the linearity of the calibration curve $\left(r^{2}\right)$ was $>0.99$ for each analyte.

\subsection{Statistical analysis}

Statistical analysis of the data was conducted using SPSS version 17.0 (SPSS Inc. 2009). Geometric mean (GM), median and concentration range were used to describe the concentrations of the target analytes. All data were reported on a dry weight basis. Analyte concentrations under MQLs were set as MQLs divided by the square root of 2. The results from Shapiro-Wilk and Kolmogorov-Smirnov tests, combined with visual inspection of frequency diagrams, revealed concentrations in all data sets to be log-normally distributed. Hence, further analysis of Student's $t$-test was performed on log-transformed concentrations to check the concentration difference between samples. Pearson's correlation analysis (2-tailed) was used to test the relationship among different target analytes. Results were considered significant with $p<0.05$. The total concentration of SPAs ( $\sum$ SPAs) was the sum concentrations of all the target antioxidants analyzed in this study, whereas those of TPs were not included. The composition profile of the detected SPAs was expressed as percent contribution of individual SPA analogue to total concentration.

\section{Results and discussion}

\subsection{SPA concentrations and composition profiles in dust samples}

As shown in Table 1, seven SPA analogues including BHT, BHA, 4tOP, AO 246, DBP, DTBSBP and AO 44B25 could be detected in the dust samples with concentrations from $<$ MQLs to $1.84 \mathrm{e} 4 \mathrm{ng} / \mathrm{g}$. The concentration of $\sum$ SPAs in the samples varied from $668 \mathrm{ng} / \mathrm{g}$ to $2.03 \mathrm{e} 4 \mathrm{ng} / \mathrm{g}$, with a GM value of $2.76 \mathrm{e} 3 \mathrm{ng} / \mathrm{g}$. For the 75 dust samples, BHT was the dominant SPA analogue, accounting for $11-96 \%$ of $\sum$ SPAs (average value: $66 \%$ ), which was followed by AO
246 (22\%), DBP (5.5\%), 4-tOP (3.2\%), BHA (2.3\%), DTBSBP (2.2\%) and AO 44B25 (0.1\%). The observed composition pattern in the dust samples was well corresponding to the SPA production volumes. As reported, BHT accounts for $80 \%$ of the total SPA production and usage in China (Du and Guo, 2009). Besides, the other high concentration detected SPAs in this study (AO 246, DBP, DTBSBP, and 4tOP) are included in the OECD HPV chemical list (OECD, 2015).

Among the SPA analytes, BHT was detectable in all of the investigated urban $(\mathrm{n}=55)$ and rural dust samples $(\mathrm{n}=20)$ with concentrations of $852-1.84 \mathrm{e} 4 \mathrm{ng} / \mathrm{g}$ (GM: $2.27 \mathrm{e} 3 \mathrm{ng} / \mathrm{g}$ ) and 163-2.33e3 ng/g (GM: $773 \mathrm{ng} / \mathrm{g}$ ), respectively. Limited studies showed that BHT existed in dust samples with concentrations from $170 \mathrm{ng} / \mathrm{g}$ to 7.00e4 ng/g (Nilsson et al., 2005; Wang et al., 2016). High concentrations of BHT (230-1.30e $3 \mathrm{ng} / \mathrm{g})$ were also reported in human body fat in UK and USA (Collings and Sharratt, 1970), though no study investigated the relationship between the BHT occurrence in human body and its exposure through dust ingestion. High detection frequencies were found for BHA in urban (89\%) and rural dust samples (100\%) in this study with GM concentrations of $12.0 \mathrm{ng} / \mathrm{g}$ and $84.0 \mathrm{ng} / \mathrm{g}$, respectively. While, one previous study showed that, for the dust samples collected from 12 countries, BHA was exclusively in samples from China (Wang et al., 2016). Sporadic studies were found reporting the occurrence of 4-tOP in settled house dust matrix from China with median concentration of $80.0 \mathrm{ng} / \mathrm{g}$ (Lu et al., 2013). In the present study, the GM concentrations of 4-tOP in urban and rural dust samples were $28.0 \mathrm{ng} / \mathrm{g}$ and $2.18 \mathrm{ng} / \mathrm{g}$, which were lower than the previously reported ones.

Besides the above compounds, some novel SPA analogues that were not previously reported in dust matrix such as AO 246 and DTBSBP, were also observed in this study. As shown in Table S1, compared with the most frequently investigated SPAs (BHT, BHA and 4-tOP), most of the novel SPA analogues have relatively higher hydrophobicity ( $\left.\lg K_{o w}, 5.33-17.2\right)$ and lower volatilities (lg $K_{o a}$, 9.01-30.3). Thus, they are more inclined to absorb on indoor dust and accumulate in human body through dust ingestion. Results showed that AO 246 was positively identified in all the collected urban and rural dust samples with concentrations of 10.3-1.16e3 ng/g (GM: $229 \mathrm{ng} / \mathrm{g}$ ) and 208-2.87e3 ng/g (GM: $834 \mathrm{ng} / \mathrm{g}$ ), respectively. High bioconcentration factors $(B C F=4320-23200)$ of AO 246 were observed in fish (Adolfsson-Erici et al., 2012), thus its occurrence in indoor dust and the human exposure via dust ingestion worth attention. As an isomer of AO 246, DTBSBP was also detected in most urban (76\%) and rural samples (100\%) with concentrations of $<\mathrm{MQL}-238 \mathrm{ng} / \mathrm{g}$ (GM: $21.0 \mathrm{ng} / \mathrm{g}$ ) and $17.2-148 \mathrm{ng} / \mathrm{g}$

Table 1

The concentrations (ng/g) and other relevant information of the detected SPAs in the urban and rural indoor dust samples.

\begin{tabular}{|c|c|c|c|c|c|c|c|c|c|}
\hline Microenvironment & & BHT & BHA & $4-t \mathrm{OP}$ & AO 246 & DBP & DTBSBP & AO 44B25 & $\sum \mathrm{SPAS}$ \\
\hline \multirow[t]{5}{*}{ Urban houses $(\mathrm{n}=55)$} & $\mathrm{GM}^{\mathrm{a}}$ & $2.27 \mathrm{e} 3$ & 12.0 & 28 & 229 & 67.0 & 21.0 & 1.40 & $3.12 \mathrm{e} 3$ \\
\hline & median & $1.88 \mathrm{e} 3$ & 14.2 & 42.1 & 266 & 324 & 37.9 & 1.06 & $2.56 \mathrm{e} 3$ \\
\hline & range & $852-18.4 \mathrm{e} 3$ & $<$ MQL-152 & $<$ MQL -900 & $10.3-1.16 \mathrm{e} 3$ & $20.0-1.13 \mathrm{e} 3$ & $<$ MQL-238 & $<$ MQL-51.6 & $1.56 \mathrm{e} 3-2.03 \mathrm{e} 4$ \\
\hline & $\mathrm{DF}^{\mathrm{b}}(\%)$ & 100 & 89 & 80 & 100 & 84 & 76 & 16 & - \\
\hline & $\mathrm{AP}^{\mathrm{C}}(\%)$ & 74 & 0.6 & 4.2 & 12 & 7.3 & 1.9 & 0.1 & 100 \\
\hline \multirow{5}{*}{$\begin{array}{l}\text { Rural houses } \\
(\mathrm{n}=20)\end{array}$} & $\mathrm{GM}^{\mathrm{a}}$ & 773 & 84 & 2.18 & 834 & 4.22 & 56.6 & 1.06 & $1.97 \mathrm{e} 3$ \\
\hline & median & 998 & 73.8 & 0.93 & 759 & 8.73 & 51.5 & 1.06 & $1.89 \mathrm{e} 3$ \\
\hline & range & $163-2.33 \mathrm{e} 3$ & $9.52-887$ & $<$ MQL -52.2 & $208-2.82 \mathrm{e} 3$ & $<$ MQL -45.7 & $17.2-148$ & $<\mathrm{MQL}$ & $668-4.39 \mathrm{e} 3$ \\
\hline & $\mathrm{DF}^{\mathrm{b}}(\%)$ & 100 & 100 & 30 & 100 & 55 & 100 & 0 & - \\
\hline & $\operatorname{AP}^{\mathrm{C}}(\%)$ & 43 & 7.0 & 0.4 & 46 & 0.7 & 3.2 & 0 & 100 \\
\hline \multirow{5}{*}{$\begin{array}{l}\text { All dust samples } \\
(\mathrm{n}=75)\end{array}$} & $\mathrm{GM}^{\mathrm{a}}$ & $1.70 \mathrm{e} 3$ & 20.1 & 14.0 & 323 & 32.0 & 27.3 & 1.30 & $2.76 \mathrm{e} 3$ \\
\hline & median & $1.59 \mathrm{e} 3$ & 20.0 & 20.0 & 413 & 67.6 & 46.3 & 1.06 & 2.31 \\
\hline & range & $163-18.4 \mathrm{e} 3$ & $<$ MQL -887 & $<$ MQL -900 & $10.3-2.82 \mathrm{e} 3$ & $<\mathrm{MQL}-1.13 \mathrm{e} 3$ & $<\mathrm{MQL}-238$ & $<$ MQL -51.6 & $668-20.3 e 3$ \\
\hline & $\mathrm{DF}^{\mathrm{b}}(\%)$ & 100 & 92 & 67 & 100 & 76 & 83 & 12 & - \\
\hline & $\mathrm{AP}^{\mathrm{C}}(\%)$ & 66 & 2.3 & 3.2 & 22 & 5.5 & 2.2 & 0.1 & 100 \\
\hline
\end{tabular}

\footnotetext{
${ }^{\text {a }}$ GM: Geometric mean.

b DF: Detection frequency.

c AP: Averaged proportion.
} 
(GM: $56.6 \mathrm{ng} / \mathrm{g}$ ), respectively. Pearson correlation analysis showed that strong relationship $(\mathrm{R}=0.689, p<0.01)$ was found between the concentrations of AO 246 and DTBSBP in the dust samples, which might imply their common input sources and/or similar environmental behaviors. DBP was used in the production of antioxidants and ultraviolet absorbers, and was found in vegetable, meat and fish samples with concentrations up to $34.2 \mathrm{ng} / \mathrm{g}$ in Japan (Nemoto et al., 2001). It can be activated by oxygen to form a reactive quinone or dimer, and affect extra- or intracellular bioactive materials, resulting in the induction of cytotoxicity (Saito et al., 2001). In the present study, DBP was detected in the urban and rural indoor dust samples with GM concentrations of $67.0 \mathrm{ng} / \mathrm{g}$ and $4.22 \mathrm{ng} / \mathrm{g}$, respectively. For the poly-phenolic ring SPAs, only AO $44 \mathrm{~B} 25$ was positively identified in nine urban dust samples with concentrations varying from < MQL to $51.6 \mathrm{ng} / \mathrm{g}$ (GM: $1.30 \mathrm{ng} / \mathrm{g}$ ). This is consistent with the SPA composition profile in sludge matrix that the concentrations of single phenolic ring SPAs (BHT, BHA, 4tOP, AO 246, DTBSBP, and DBP) were much higher than the polyphenolic ring SPAs (Liu et al., 2015b). The poly-phenolic ring SPAs such as AO 2246, AO 22E46, AO 330, AO 425, and AO 4426, which were sporadically detected with low concentrations (GM: $0.11-11.4 \mathrm{ng} / \mathrm{g}$ ) in sludge samples from China, were not found in urban or rural indoor dust samples in the present study. The low detection frequency and concentration level of the poly-phenolic ring SPAs in dust samples might due to their little usage in Chinese houses and/or low migration levels from polymeric materials.

\subsection{Occurrence of the BHT transformation products in dust samples}

In contrast to the controversial health effects of BHT consumption, some TPs of BHT were proved to have adverse toxic effects (Oikawa et al., 1998). For example, BHT-Q can cause internucleosomal DNA fragmentation through $\mathrm{H}_{2} \mathrm{O}_{2}$ and oxygen radical generation. And quite low concentration of BHT-Q $\left(10^{-6} \mathrm{M}\right)$ can cause DNA cleavage in vitro study (Nagai et al., 1993). The enhanced toxicological effects of the TPs compared to the precursor (BHT) forced us to pay attention to their occurrence and possible exposure to human through dust ingestion.

Previous studies showed that BHT can be oxidized under visiblelight photo-irradiation, through no transformation product was given out (Criado et al., 2007). In the present study, as shown in Table S5, BHT-CHO was detected in most of the urban (98\%) and rural dust samples (100\%) with concentrations of $<\mathrm{MQL}-1.04 \mathrm{e} 3$ ng/g (GM: $48 \mathrm{ng} / \mathrm{g}$ ) and 3.17-76.4 ng/g (GM: $15.1 \mathrm{ng} / \mathrm{g}$ ), respectively. BHT-Q was positively identified in all the investigated urban and rural dust samples with concentrations of $8.56-1.96 \mathrm{e} 3 \mathrm{ng} / \mathrm{g}$ (GM: $246 \mathrm{ng} / \mathrm{g}$ ). BHT-quinol, which was not previously reported in dust matrix, was detected in $100 \%$ of the urban and $90 \%$ of rural dust samples with GM concentrations of $203 \mathrm{ng} / \mathrm{g}$ and $20.0 \mathrm{ng} / \mathrm{g}$, respectively. For the 75 dust samples, BHT-Q was the prominent transformation product accounting for $51 \%$ of $\sum$ TPs, which was followed by BHT-quinol (33\%) and BHT-CHO (15\%). The concentrations of $\sum$ TPs (sum of the three TPs) ranged from $17.8 \mathrm{ng} / \mathrm{g}$ to $4.46 \mathrm{e} 3 \mathrm{ng} / \mathrm{g}$ (GM: $377 \mathrm{ng} / \mathrm{g}$ ). The GM concentration of $\sum$ TPs equals to $22 \%$ of the BHT content, which was generally in agreement with the previous finding that the concentration of $\sum$ TPs accounted for more than $20 \%$ of BHT in sludge matrix in China (Liu et al., 2015b). Furthermore, both rural and urban home dust showed the concentrations of TPs in the following order: BHT-Q > BHTquinol > BHT-CHO, which was similar to the previous finding in sewage sludge samples. That might implied the similar transformation pathway of BHT in different microenvironments. Moreover, the occurrence of BHT-CHO, BHT-Q and BHT-quinol in dust matrix might indicate that photo-induced reaction could be important oxidation process in the transformation fate of SPAs, besides the aerobic oxidation in the wastewater treatment plant (Liu et al., 2015b). Given the universal detection and enhanced toxicological effects of these TPs, attention should be paid to the environmental or human health risk.

\subsection{Varied abundances of SPA analogues between urban and rural dust samples}

In order to further elucidate sources of target SPAs in indoor dust, the collected samples were stratified as urban house dust and rural house dust. As shown in Table 1, significantly higher GM concentration $(p<0.05)$ was observed for $\sum$ SPAs in urban house dust (GM: $3.12 \mathrm{e} 3 \mathrm{ng} / \mathrm{g}$ ) than that in rural house dust (GM: 1.97e3 $\mathrm{ng} / \mathrm{g}$ ). SPAs are largely used as additives in rubber, elastomers and plastic (Lanigan and Yamarik, 2002). Thus, the higher concentration of $\sum$ SPAs in urban indoor dust might result from more usage of furniture and electronics such as TV, washer and refrigerator in urban homes. Similar phenomenon was found in other studies that significantly higher concentrations of benzotriazole, benzothiazole, and benzophenone were found in urban home dust compared with rural home dust in China (Wang et al., 2013). As shown in Fig. 1, urban indoor dust (GM: $555 \mathrm{ng} / \mathrm{g}$ ) showed significantly higher $(p<0.05)$ concentration of $\sum$ TPs than rural indoor dust (GM: $131 \mathrm{ng} / \mathrm{g})$. Besides, significant correlation $(p<0.01)$ between the concentrations of BHT and $\sum$ TPs was observed in the dust samples.

As shown in Fig. 2, the composition profiles of SPAs varied substantially between the two microenvironments. BHT dominated the SPA composition in the urban house dust, which accounted for $74 \%$ of the $\Sigma$ SPAs. This was generally in agreement with the previous findings that BHT was of the first abundance in sludge and water samples (Liu et al., 2015a, 2015b). Rural home dust, however, showed different analogue composition that AO 246 (46\%) and BHT (43\%) showed similar contributions to $\sum$ SPAs. Besides, though the concentration of $\sum$ SPAs was much higher in urban dust than in rural dust, there was opposite result for some SPA analogues including BHA, AO 246 and DTBSBP, which have significantly higher concentrations $(p<0.05)$ in rural dust samples compared with the urban samples. This might result from the different sources and applications of target SPAs in various types of microenvironments.

\subsection{Human exposure to SPAs and transformation products via indoor dust ingestion}

Dust ingestion is a significant exposure route to humans for environmental pollutants (Richards et al., 2016). Inhaled dust caused adverse health effects in many ways, in which the generation of hydrogen peroxide was vital. Quinones in dust samples were demonstrated to be among the chemicals which are responsible to the generation of hydrogen peroxide in surrogate lung fluid (Charrier et al., 2014). Given the universal detection of quinone transformation product of BHT (BHT-Q) and other SPAs in the collected dust samples, it is important to calculate the estimated daily intake (EDI) of SPAs and TPs through indoor dust ingestion. The EDI was calculated from the equation as below:

$\mathrm{EDI}=\mathrm{C} \times \mathrm{m} / \mathrm{bw}$

Where " $\mathrm{m}$ " is the indoor dust ingestion rate (g/day), "bw" is the body weight ( $\mathrm{kg})$, and " $\mathrm{C}$ " is the concentration of target analyte. The body weights for children $(28.2 \mathrm{~kg})$ and adults $(62.9 \mathrm{~kg})$ in China were adopted from a previous study (CNPMC, 2012), and " $\mathrm{m}$ " of 0.06 and $0.03 \mathrm{~g} / \mathrm{d}$ was used, as recommended by the U.S. EPA (EPA, 2011). Based on GM concentrations of these compounds, the GM EDIs for children and adults were calculated. The high EDIs were calculated based on the 95th percentile concentrations of the 


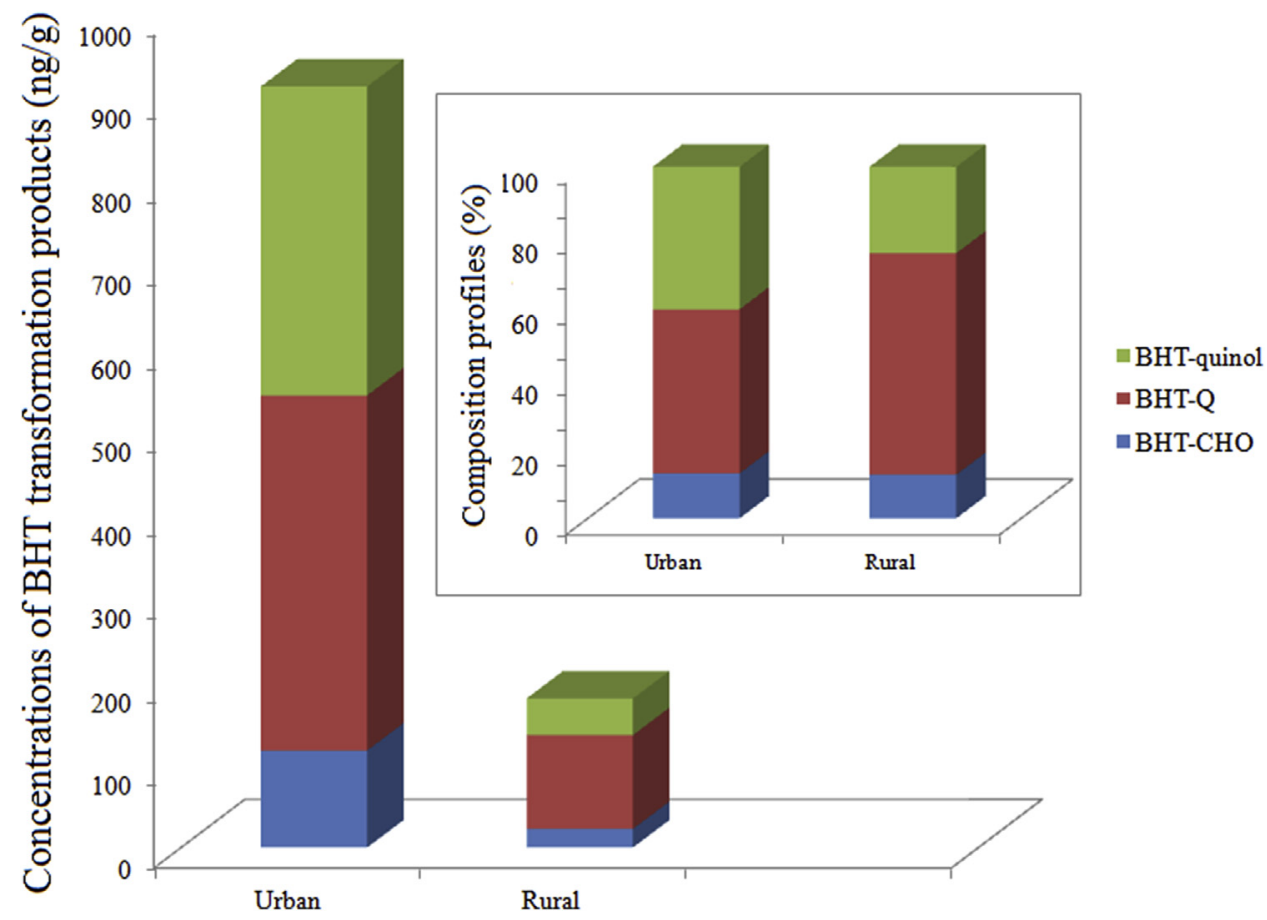

Fig. 1. Concentrations and composition profiles of the detected TPs in urban and rural home dust samples.

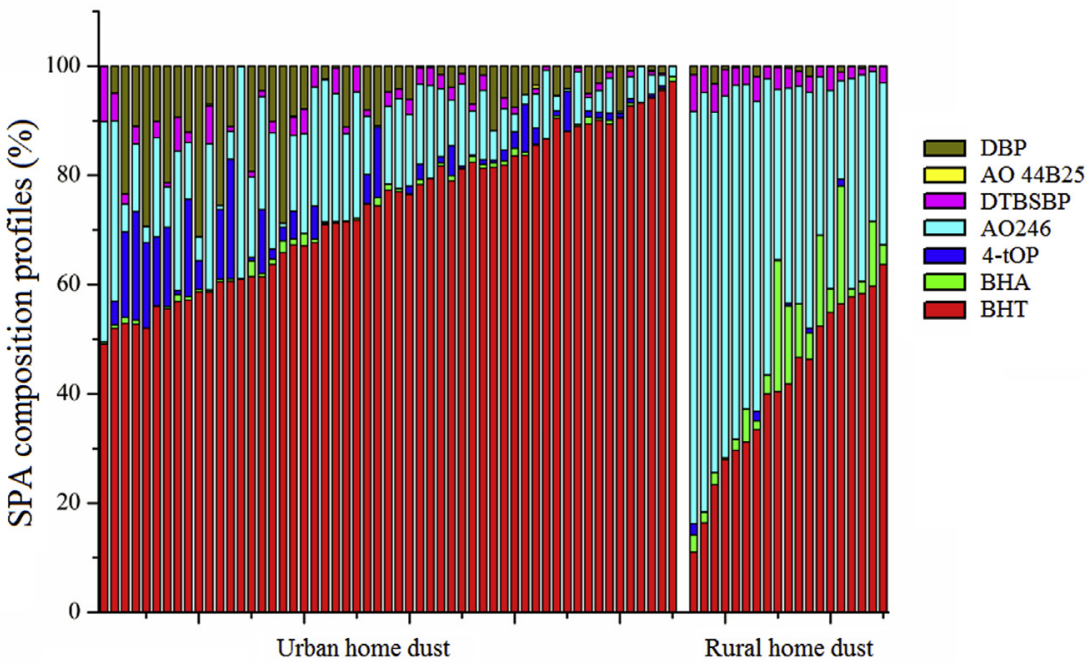

Fig. 2. The composition profiles of individual SPA analogue in urban and rural indoor dust sample.

compounds (Liao et al., 2012). As shown in Table 2, the GM of $\sum$ SPAs EDIs for urban children and adults were 6.64 and $1.49 \mathrm{ng} /$ $\mathrm{kg}$ bw/day, respectively. The EDIs of $\sum$ TPs varied from sub to $\mathrm{ng} /$ $\mathrm{kg}$ bw/day for urban children (GM: $1.18 \mathrm{ng} / \mathrm{kg}$ bw/day) and adults
(GM: $0.26 \mathrm{ng} / \mathrm{kg}$ bw/day). Lower EDIs of $\sum$ SPAs and $\sum$ TPs were found for rural children and adults. Compared with the EDIs of BHT by food intakes in Korea ( $40 \mu \mathrm{g} / \mathrm{kg}$ bw/day) and America $(0.39 \mathrm{mg} / /$ $\mathrm{kg}$ bw/day) (FAO/WHO, 2000; Nieva-Echevarria et al., 2015), the

Table 2

Estimated daily intakes (EDI, ng/kg bw/day) of SPAs and transformation products by ingestion of indoor dust for children and adults in the China.

\begin{tabular}{|c|c|c|c|c|c|c|c|c|}
\hline \multirow[t]{3}{*}{ Compounds } & \multicolumn{4}{|c|}{ Urban } & \multicolumn{4}{|c|}{ Rural } \\
\hline & \multicolumn{2}{|c|}{ Children } & \multicolumn{2}{|c|}{ Adults } & \multicolumn{2}{|c|}{ Children } & \multicolumn{2}{|c|}{ Adults } \\
\hline & GM & $95^{\text {th }}$ percentile & GM & $95^{\text {th }}$ percentile & GM & $95^{\text {th }}$ percentile & GM & $95^{\text {th }}$ percentile \\
\hline BHT & 4.83 & 7.97 & 1.08 & 1.79 & 1.64 & 2.64 & 0.37 & 0.59 \\
\hline$\sum$ SPAs & 6.64 & 9.83 & 1.49 & 2.20 & 4.19 & 5.74 & 0.94 & 1.29 \\
\hline$\sum \mathrm{TPS}$ & 1.18 & 2.52 & 0.26 & 0.56 & 0.28 & 0.52 & 0.06 & 0.12 \\
\hline
\end{tabular}


EDI of BHT by dust digestion (4.83 and $1.08 \mathrm{ng} / \mathrm{kg}$ bw/day for urban children and adults) was much lower. Acceptable daily intakes (ADIs) for most of the SPAs were not available. Only the ADI of BHT was recommended as $0.25 \mathrm{mg} / \mathrm{kg}$ bw/day by European Food Safety Authority (Lanigan and Yamarik, 2002), which was much higher than the EDI of BHT measured in this study at dust ingestion scenario. Thus the results indicate that current human exposure to BHT via ingestion of indoor dust might not pose an immediate health risk to the Chinese population based on the current state of knowledge about the toxicological properties of BHT.

However, due to the occurrence of novel SPA analogues (AO 246, DTBSBP, DBP and AO 44B25), which accounted 6-84\% (averaged: $29 \%$ ) of $\sum$ SPAs, the EDI of $\sum$ SPAs was much higher than that of BHT (Table 2). Synergistic effect was reported in the induction of apoptosis between BHT and BHA (Saito et al., 2003). Thus, attention should be paid to simultaneous exposure to BHT, BHA and the novel SPA analogues with high hydrophobicity. Besides, as BHT-Q belongs to quinone which could produce hydrogen peroxide, its potential adverse effect through dust inhalation should be worthy of note as well.

\section{Conclusions}

In this study, seven SPA analogues and three TPs were positively identified in most of the 75 dust samples collected from urban and rural homes in Shandong Province of China, indicating their widespread presence in indoor environments. Significantly higher concentrations $(p<0.05)$ of $\sum$ SPAs and $\sum$ TPs were found in urban indoor dust than in rural samples. Different SPA composition profiles were found between urban and rural indoor dust. BHT was the dominate analogue in the urban indoor dust, which constituted $74 \%$ of $\Sigma$ SPAs, while AO 246 (46\%) and BHT (43\%) had similar contributions to $\sum$ SPAs in rural indoor dust. Attention should be paid to detection of novel SPA analogues with relatively higher hydrophobicity and persistency (AO 246, DTBSBP, DBP and AO 44B25) in indoor dust, which accounted for $29 \%$ of $\sum$ SPA. Human exposure to SPAs via ingestion of indoor dust was calculated, with EDI of $\sum$ SPAs of $0.37-7.97 \mathrm{ng} / \mathrm{kg}$ bw/day. More detailed studies are required to fully characterize the overall human exposure to SPAs via other exposure pathways including inhalation and dermal exposure.

\section{Acknowledgement}

This work was jointly supported by the National Natural Science Foundation (21622705, 21577151), the Strategic Priority Research Program of the Chinese Academy of Sciences (Grant No. XDB14010400), and Youth Innovation Promotion Association CAS projects.

\section{Appendix A. Supplementary data}

Supplementary data related to this article can be found at http:// dx.doi.org/10.1016/j.envpol.2016.11.069.

\section{References}

Adolfsson-Erici, M., Akerman, G., McLachlan, M.S., 2012. Measuring bioconcentration factors in fish using exposure to multiple chemicals and internal benchmarking to correct for growth dilution. Environ. Toxicol. Chem. 31, 1853-1860.

Botterweck, A.A.M., Verhagen, H., Goldbohm, R.A., Kleinjans, J., van den Brandt, P.A., 2000. Intake of butylated hydroxyanisole and butylated hydroxytoluene and stomach cancer risk: results from analyses in The Netherlands cohort study. Food Chem. Toxicol. 38, 599-605.

Brocca, D., Arvin, E., Mosbaek, H., 2002. Identification of organic compounds migrating from polyethylene pipelines into drinking water. Water Res. 36, 3675-3680.
Charrier, J.G., McFall, A.S., Richards-Henderson, N.K., Anastasio, C., 2014. Hydrogen peroxide formation in a surrogate lung fluid by transition metals and quinones present in particulate matter. Environ. Sci. Technol. 48, 7010-7017.

CNPMC, 2012. Chinese National Physique Monitoring Communique 2010 (In Chinese) (accessed 26 November 2015). http://www.gov.cn/test/2012-04/19/ content_2117320.htm.

Collings, A.J., Sharratt, M., 1970. The BHT content of human adipose tissue. Food Cosmet. Toxicol 8, 409-412.

Criado, S., Allevi, C., Ceballos, C., Garcia, N.A., 2007. Visible-light promoted degradation of the commercial antioxidants butylated hydroxyanisole (BHA) and butylated hydroxytoluene (BHT): a kinetic study. Redox Rep. 12, 282-288.

Demertzis, P.G., Franz, R., 1998. Development of an HPLC method for measurements of the stability of Irganox-type polymer antioxidants in fatty food simulants. Z. Lebensm. Unters. Forsch. A 206, 193-198.

Du, F., Guo, F., 2009. Research progress in antioxidant of bridged alkyl phenols category and its derivates used for synthetic rubber (in Chinese). China Synth. Rubber Ind. 32, 352-354.

EPA, 2011. Exposure Factors Handbook: 2011 edition. United States Environmental Protection Agency, Office of Research and Development C. 2011, Washington, dc (accessed 26 November 2015). http://www.epa.gov/ncea/efh/pdfs/efhcomplete.pdf.

FAO/WHO, 2000. Evaluation of certain food additives. Fifty-first report of the joint FAO/WHO expert committee on food additives. World Health Organization. Tech. Rep. Ser. 891, 1-168.

Fries, E., Puttmann, W., 2004. Monitoring of the antioxidant BHT and its metabolite BHT-CHO in German river water and ground water. Sci. Total Environ. 319, 269-282.

Gao, Y.L., Gu, Y.X., Wei, Y., 2011. Determination of polymer additives-antioxidants and ultraviolet (UV) absorbers by high-performance liquid chromatography coupled with UV photodiode array detection in food simulants. J. Agric. Food Chem. 59, 12982-12989.

Grice, H.C., 1988. Safety evaluation of butylated hydroxyanisole from the perspective of effects on forestomach and esophageal squamous epithelium. Food Chem. Toxicol. 26, 717-723.

Howard, P.H., Muir, D.C.G., 2010. Identifying new persistent and bioaccumulative organics among chemicals in commerce. Environ. Sci. Technol. 44, 2277-2285.

Klepeis, N.E., Nelson, W.C., Ott, W.R., Robinson, J.P., Tsang, A.M., Switzer, P. Behar, J.V., Hern, S.C., Engelmann, W.H., 2001. The national human activity pattern survey (NHAPS): a resource for assessing exposure to environmental pollutants. J. Expo. Anal. Environ. Epidemiol. 11, 231-252.

Lanigan, R.S., Yamarik, T.A., 2002. Final report on the safety assessment of BHT. Int. J. Toxicol. 21, 19-94.

Liao, C., Liu, F., Guo, Y., Moon, H.B., Nakata, H., Wu, Q., Kannan, K., 2012. Occurrence of eight bisphenol analogues in indoor dust from the United States and several Asian countries: implications for human exposure. Environ. Sci. Technol. 46, 9138-9145.

Liu, R.Z., Lin, Y.F., Hu, F.B., Liu, R.R., Ruan, T., Jiang, G.B., 2016. Observation of emerging photoinitiator additives in household environment and sewage sludge in China. Environ. Sci. Technol. 50, 97-104.

Liu, R.Z., Ruan, T., Song, S.J., Lin, Y.F., Jiang, G.B., 2015a. Determination of synthetic phenolic antioxidants and relative metabolites in sewage treatment plant and recipient river by high performance liquid chromatography- electrospray tandem mass spectrometry. J. Chromatogr. A 1381, 13-21.

Liu, R.Z., Song, S.J., Lin, Y.F., Ruan, T., Jiang, G.B., 2015b. Occurrence of synthetic phenolic antioxidants and major metabolites in municipal sewage sludge in China. Environ. Sci. Technol. 49, 2073-2080.

Lu, X.M., Chen, M.J., Zhang, X.L., Sun, Y.G., Zhu, D.M., Zhang, Q., Wang, B.L. Zhang, Z.D., 2013. Simultaneous quantification of five phenols in settled house dust using ultra-high performance liquid chromatography-tandem mass spectrometry. Anal. Methods 5, 5339-5344.

Matsumoto, K., Ochiai, T., Sekita, K., Uchida, O., Furuya, T., Kurokawa, Y., 1991. Chronic toxicity of 2,4,6-tri-tert-butylphenol in rats. J. Toxicol. Sci. 16, 167-179.

Meng, G., Nie, Z.Q., Feng, Y., Wu, X.M., Yin, Y., Wang, Y., 2016. Typical halogenated persistent organic pollutants in indoor dust and the associations with childhood asthma in Shanghai, China. Environ. Pollut. 211, 389-398.

Muir, D.C.G., Howard, P.H., 2006. Are there other persistent organic pollutants? A challenge for environmental chemists. Environ. Sci. Technol. 40, 7157-7166.

Nagai, F., Ushiyama, K., Kano, I., 1993. DNA cleavage by metabolites of butylated hydroxytoluene. Arch. Toxicol. 67, 552-557.

Nemoto, S., Omura, M., Takatsuki, S., Sasaki, K., Toyoda, M., 2001. Determination of 2,4,6-tri-tert-butylphenol and related compounds in foods. J. Food Hyg. Soc. Jpn. 42, 359-366.

Nieva-Echevarria, B., Manzanos, M.J., Goicoechea, E., Guillen, M.D., 2015. 2,6-Ditert-butyl-hydroxytoluene and its metabolites in foods. Compr. Rev. Food Sci. Food Saf. 14, 67-80.

Nilsson, A., Lagesson, V., Bornehag, C.G., Sundell, J., Tagesson, C., 2005. Quantitative determination of volatile organic compounds in indoor dust using gas chromatography-UV spectrometry. Environ. Int. 31, 1141-1148.

OECD, 2015. Existing Chemical Database. Available online at:http://webnet.oecd. org/hpv/ui/Default.aspx (accessed 21 July 2015).

Oikawa, S., Nishino, K., Oikawa, S., Inoue, S., Mizutani, T., Kawanishi, S., 1998. Oxidative DNA damage and apoptosis induced by metabolites of butylated hydroxytoluene. Biochem. Pharmacol. 56, 361-370.

Qi, H., Li, W.L., Liu, L.Y., Zhang, Z.F., Zhu, N.Z., Song, W.W., Ma, W.L., Li, Y.F., 2014 Levels, distribution and human exposure of new non-BDE brominated flame 
retardants in the indoor dust of China. Environ. Pollut. 195, 1-8.

Richards, J., Reif, R., Luo, Y., Gan, J., 2016. Distribution of pesticides in dust particles in urban environments. Environ. Pollut. 214, 290-298.

Rodil, R., Quintana, J.B., Basaglia, G., Pietrogrande, M.C., Cela, R., 2010. Determination of synthetic phenolic antioxidants and their metabolites in water samples by downscaled solid-phase extraction, silylation and gas chromatography-mass spectrometry. J. Chromatogra. A 1217, 6428-6435.

Saito, M., Atsumi, T., Satoh, K., Ishihara, M., Iwakura, I., Sakagami, H., Yokoe, I. Fujisawa, S., 2001. Radical production and cytotoxic activity of tert-butylsubstituted phenols. Vitro Mol. Toxicol. 14, 53-63.

Saito, M., Sakagami, H., Fujisawa, S., 2003. Cytotoxicity and apoptosis induction by butylated hydroxyanisole (BHA) and butylated hydroxytoluene (BHT). Anticancer Res. 23, 4693-4701.

Statistical bulletin of national economic and social development for Jinan, 2014 (Available at: http://www.jinan.gov.cn/art/2015/6/16/art_179_129180.html, (in Chinese)).

Takahashi, O., Oishi, S., 2006. Male reproductive toxicity of four bisphenol antioxidants in mice and rats and their estrogenic effect. Arch. Toxicol. 80, 225-241.
Wang, L., Asimakopoulos, A.G., Moon, H.B., Nakata, H., Kannan, K., 2013. Benzotriazole, benzothiazole, and benzophenone compounds in indoor dust from the United States and east asian countries. Environ. Sci. Technol. 47, 4752-4759.

Wang, W., Asimakopoulos, A.G., Abualnaja, K.O., Covaci, A., Gevao, B., JohnsonRestrepo, B., Kumosani, T.A., Malarvannan, G., Minh, T.B., Moon, H.B., Nakata, H., Sinha, R.K., Kannan, K., 2016. Synthetic phenolic antioxidants and their metabolites in indoor dust from homes and microenvironments. Environ. Sci. Technol. 50, 428-434.

Wei, G.L. Li, D.O. Zhuo, M.N. Liao, Y.S., Xie, Z.Y, Guo, T.L, Li, J.J., Zhang, S.Y, Liang, Z.Q., 2015. Organophosphorus flame retardants and plasticizers: sources, occurrence, toxicity and human exposure. Environ. Pollut. 196, 29-46.

Whysner, J., Williams, G.M., 1996. Butylated hydroxyanisole mechanistic data and risk assessment: conditional species-specific cytotoxicity, enhanced cell proliferation, and tumor promotion. Pharmacol. Ther. 71, 137-151.

Witschi, H.P., 1986. Enhanced tumor-development by butylated hydroxytoluene (BHT) in the liver, lung and gastrointestinal-tract. Food Chem. Toxicol. 24, 1127-1130. 